\title{
Can We Tackle with Vascular Calcification and Arterial Stiffness in Patients with Chronic Kidney Disease?
}

\author{
Eirini Stavrinou, Aikaterini Papagianni*, Charalambos Koumaras, Panagiotis Pateinakis and \\ Georgios Efstratiadis
}

Department of Nephrology, Medical School, Aristotle University of Thessaloniki, Hippokration Hospital, Thessaloniki, Greece

\begin{abstract}
Cardiovascular disease remains the leading cause of increased morbidity and mortality in patients with chronic kidney disease and is attributed to early and accelerated atherosclerosis and arteriosclerosis observed in this patient population. Vascular calcifications, particularly of the media, are commonly found in chronic uremia and are a major contributor to arteriosclerosis and increased arterial stiffness. Epidemiologic data support the correlation of vascular calcification and arterial stiffness to adverse cardiovascular outcomes and mortality. Experimental evidence has shed light on the pathogenetic mechanisms of vascular calcification and arterial stiffness and their relation to impaired bone metabolism and imbalance between promoters and inhibitors of extra-osseous bone formation. However further research is needed to clarify their exact contribution and whether their targeting could significantly affect vascular calcification and arterial stiffening and could improve survival in chronic kidney disease patients.
\end{abstract}

Keywords: Arterial stiffness, bone metabolism, cardiovascular disease, chronic kidney disease, vascular calcification.

\section{INTRODUCTION}

Cardiovascular disease (CVD) remains the leading cause of increased morbidity and mortality in patients with chronic kidney disease (CKD) and particularly those on renal replacement therapy $[1,2]$. The pathogenesis of vasculopathy in CKD involves traditional risk factors of atherosclerosis (older age, hypertension, dyslipidemia, diabetes mellitus), which are highly prevalent in renal patients, but also several non-traditional or uremia-related risk factors (inflammation, oxidative stress, mineral and bone disorders), which are intensively investigated. In addition, vascular calcifications, particularly of the media, are an almost ubiquitous feature of arterial tree in chronic uremia and a major contributor to accelerated arteriosclerosis and increased arterial stiffness observed in CKD patients [3-5]. The extent of vascular calcification and the degree of arterial stiffness, closely interrelated, are non-traditional CVD risk factors and independent predictors of CVD mortality, both in general population and CKD patients [6-10]. Several studies have shown that mineral-bone disorders and imbalance between promoters and inhibitors of extra-osseous bone formation are associated with vascular calcification and affect significantly the process of arterial stiffening in renal population, potentially leading to adverse clinical outcomes [5, 11]. Moreover, it appears that there is an interaction between bone metabolism and vascular health, placing current understanding of vascular pathophysiology on a bone-vascular axis [12]. This review is focused on the pathogenetic mechanisms underlying

*Address correspondence to this author at the Aristotle University of Thessaloniki, Department of Nephrology, Hippokration Hospital, 50 Papanastasiou Str, 54642 Thessaloniki, Greece; Tel: 00302310 992856; Fax: 0030 2310 892382; Email: aikpapag@otenet.gr and aikpapag@med.auth.gr the link between vascular calcification, arterial stiffness and bone turnover, the effect of existing "anti-calcifying" and "de-stiffening" therapeutic approaches and emerging potential novel treatment strategies aimed to improve cardiovascular outcomes in CKD patients.

\section{PATHOGENETIC MECHANISMS OF VASCULAR CALCIFICATIONS AND ARTERIAL STIFFNESS}

Arterial remodeling has been associated with both atherosclerotic and arteriosclerotic vascular changes, which share some common etiologic factors. Atherosclerosis is a focal inflammatory disease, affecting primarily medium-sized arteries and is associated with increase of the arterial intimamedia thickness, plaque formation and intimal calcification leading eventually to luminal obstruction with consequent ischemic events, such as myocardial infarction and stroke. Arteriosclerosis is a diffuse disease, affecting mainly large elastic and medium-sized arteries and is characterized by media thickening and calcification resulting in progressive loss of arterial compliance and stiffening $[13,14]$. In CKD patients, atherosclerosis and arteriosclerosis often coexist, appear early and follow an accelerated course contributing to the excessive cardiovascular mortality observed in this patient population $[2,15]$.

Recent evidence suggests that vascular calcification is a highly regulated active process, and that the phenotypic trans-differentiation of vascular smooth muscle cells (VSMCs) into osteoblast-like cells is a key pathogenetic event resulting in production of bone-like structures into the arterial wall $[3,5]$. A variety of factors that influence this process have been recognized, including dysregulated mineral homeostasis and bone turnover, as well as imbalance 
between promoters and inhibitors of extra-osseous bone formation which are still under investigation [3, 5]. In chronic uremia, elevated serum phosphorus has emerged as the predominant calcification promoting factor, by exhibiting intracellular activity against vascular smooth muscle cells, which are considered the principal mediators of damage. A variety of other molecules, such as bone morphogenic protein family, Mx-2 and Wnt axis proteins and Cbfal transcription factor, acting additionally either directly or indirectly, have been shown to promote the phenotypic changes of VSMCs into osteoblast-like cells. Moreover, several local and systemic inhibitors of vascular calcification have been identified including pyrophosphate, fetuin-A, osteopontin and matrix gla protein $[4,5]$. Interestingly, a recent study in hemodialysis patients demonstrated that fetuin-A, the major circulating calcification inhibitor, has an independent significant negative correlation with arterial stiffness, assessed by carotid-femoral pulse wave velocity (cf-PWV). In contrast, osteoprotegerin (an antiosteoclast factor produced by osteoblasts, vascular endothelial and smooth muscle cells) was found to be positively associated with PWV [16].

Recent epidemiologic data indicate a crosslink between vascular calcification and bone loss, both in general population and CKD patients [17]. Thus, in hemodialysis patients vascular calcifications have been found to be associated with osteoporosis and bone fractures [18]. Moreover recently, the Baltimore Longitudinal Study of Aging demonstrated that arterial stiffness has an inverse, age-independent, relation to cortical bone area in women, after adjustment for relevant covariates including mean arterial pressure, obesity, renal function, menopause and serum calcium [19]. Emerging experimental evidence suggests that some inhibitors of the canonical signalling Wnt pathway, which is actively involved in bone formation and vascular calcification, such as secreted frizzled Proteins (SFRPs) 2 and 4 and Dickkopf related protein-1 (DKK-1), play a role linking vascular calcification and bone. SFRPs were found to be over-expressed in areas of severe vascular calcification $[12,20,21]$, probably indicating a feedback vascular defence mechanism triggered in order to attenuate mineralization in the calcified arterial wall. However, as the SFRPs are secreted circulating proteins, they may act not only locally, but also systemically, and may impair bone mineralization, resulting in reduced bone mass. The role of sclerostin (another inhibitor of the Wnt axis produced by osteocytes) in vascular calcification is also unclear and currently under investigation. In a recent cohort study of CKD patients, elevated sclerostin levels were found to be associated with aortic calcification. However, multivariate analysis revealed an inverse relationship between sclerostin and aortic calcification [22]. Another study in postmenopausal women, showed a positive correlation between sclerostin and abdominal aortic calcification as well as pulse wave velocity [23].

Despite accumulating evidence supporting the connection between vascular calcification, arterial stiffness, low bone turnover and mortality, further research on the vascular-bone axis is required to identify the underlying pathophysiologic mechanisms and to clarify whether vascular calcification and osteoporosis should be considered modifiable determinants of cardiovascular disease.

\section{"ANTI-CALCIFYING" AND "DE-STIFFENING" TREATMENT STRATEGIES IN CKD PATIENTS}

It is well established that in CKD patients mineral and bone disorders contribute to medial calcification and arterial stiffening, thus representing a treatment goal. Particularly, control of hyperphosphatemia and secondary hyperparathyroidism, appear to be associated with amelioration of vascular calcifications and improved survival [24]. In this context, sevelamer, a non-calcium based phosphate binder, was associated with smaller pulse wave velocity increase [25] and when compared with calcium containing binders, with slower rates of coronary arteries calcification in hemodialysis patients, in some, although not all, relevant trials [26, 27]. ADVANCE Study (A Randomized Study to Evaluate the Effects of Cinacalcet plus Low-Dose Vitamin D on Vascular Calcification in Subjects with Chronic Kidney Disease Receiving Haemodialysis) assigned 360 prevalent hemodialysis patients, with moderate to severe secondary hyperparathyroidism, to cinacalcet plus low-dose vitamin D or flexible doses of vitamin D sterols for 52 weeks. The progression of coronary artery and cardiac valve calcification scores were lower in the cinacalcet plus vitamin D group, especially in aortic valve [28]. Moreover, a post-hoc analysis reported attenuated progression of cardiovascular calcification in the cinacalcet plus vitamin D group [29]. However, it should be noted that different vitamin $\mathrm{D}$ receptor activators appear to exert variable effects on vascular calcification, in a dosedependent manner. Thus in an experimental model of CKD, therapeutic doses of calcitriol and paricalcitol for secondary hyperparathyroidism were protective against aortic calcification, whereas higher doses were associated with inverse results [30].

Arterial stiffness is a well-established non-traditional cardiovascular risk factor [31]. Therefore, the probable beneficial effect of several antihypertensive and other agents, known to affect arterial function, on markers of arterial stiffness has been investigated [32]. Antihypertensive drugs, particularly renin-angiotensin-aldosterone system inhibitors, were shown to exert favourable effects on arterial stiffness and central blood pressure indices [33]. A study in end-stage CKD patients demonstrated that the absence of pulse wave velocity decrease in response to blood pressure decrease was an independent predictor of all-cause and cardiovascular mortality. Moreover, the use of angiotensin-converting enzyme inhibitors had a favourable effect on survival that was independent of blood pressure changes [34]. These findings are in agreement with the results of the Conduit Artery Functional Evaluation (CAFE) study in 2073 hypertensive patients. Amlodipine +/- perindopril-based therapy was shown to be superior to atenolol +/- thiazide, -based therapy, in decreasing central aortic pulse pressure, despite equally reducing brachial blood pressure. Notably, the difference between the two regimens was sustained over the 4 year follow-up [35]. Spironolactone, an aldosterone antagonist, as an add-on therapy to either angiotensin-converting enzyme inhibitors or angiotensin receptor blockers versus placebo, was found to improve arterial stiffness in CKD patients with good blood pressure control [36].

The potential impact of lipid-lowering agents on arterial stiffness in CKD patients has been poorly investigated. A 
study in early-stage CKD patients reported that atorvastatin administration for 3 years was associated with stabilization of aortic pulse wave velocity whereas the latter increased significantly in patients on placebo; however, no differences were noted between the two groups in the rate of change of aortic augmentation index or central pulse pressure [37].

\section{FUTURE PERSPECTIVES}

Advances in molecular biology could provide alternative therapeutic options aimed to prevent or ameliorate vascular calcifications and to improve arterial structural and functional abnormalities, both in general population and CKD patients. Denosumab, a monoclonal antibody to RANKL, which mimicks the action of osteoprotegerin, appears a promising "anti-calcifying" agent [38]. Also, a humanized monoclonal antibody (AMG 785) that inhibits the action of sclerostin was found to increase bone formation in healthy subjects compared to placebo [39]. Although both regulators of bone metabolism have been administered for the treatment of osteoporosis, any assuming effect on vascular calcification in CKD patients remains to be established. Potential therapeutic role for other mediators of calcification, such as pyrophosphate, fetuin A and bone morphogenic proteins also deserve further investigation.

\section{CONCLUSIONS}

Accelerated vascular calcifications and arterial stiffness considerably contribute to the increased cardiovascular morbidity and mortality observed in CKD patients. Mineral-bone disorders and dysregulation of promoters and inhibitors of extraosseous bone formation have recently received growing attention, as significant determinants of these processes. Moreover, recent clinical and experimental data indicate a crosslink between vascular calcification and bone loss, both in general population and CKD patients. Better understanding of the complex underlying mechanisms linking bone metabolism and vascular health would hopefully offer new and more effective "anti-calcifying" and "de-stiffening" treatment options aimed to reduce cardiovascular mortality in renal population.

\section{CONFLICT OF INTEREST}

The author(s) confirm that this article content has no conflicts of interest.

\section{ACKNOWLEDGEMENT}

Declared none.

\section{REFERENCES}

[1] Go AS, Chertow GM, Fan D, McCulloch CE, Hsu CY. Chronic kidney disease and the risks of death, cardiovascular events, and hospitalization. N Engl J Med 2004; 351: 1296-305.

[2] Tonelli M, Wiebe N, Culleton B, et al. Chronic kidney disease and mortality risk: a systematic review. J Am Soc Nephrol 2006; 17: 2034-47.

[3] Moe SM, Chen NX. Mechanisms of vascular calcification in chronic kidney disease. J Am Soc Nephrol 2008; 19: 213-6.

[4] Cannata-Andía JB, Rodríguez-García M, Carrillo-López N, NavesDíaz M, Díaz-López B. Vascular calcifications: pathogenesis, management, and impact on clinical outcomes. J Am Soc Nephrol. 2006; 17: S267-73.
[5] Román-García $P$, Rodríguez-García $M$, Cabezas-Rodríguez I, López-Ongil S, Díaz-López B, Cannata-Andía JB. Vascular calcification in patients with chronic kidney disease: types, clinical impact and pathogenesis. Med Princ Pract 2011; 20: 203-12.

[6] Keelan PC, Bielak LF, Ashai K, et al. Long-term prognostic value of coronary calcification detected by electron-beam computed tomography in patients undergoing coronary angiography. Circulation 2001; 104: 412-7.

[7] Vlachopoulos C, Aznaouridis K, Stefanadis C. Prediction of cardiovascular events and all-cause mortality with arterial stiffness: a systematic review and meta-analysis. J Am Coll Cardiol 2010; 55: 1318-27.

[8] Blacher J, Safar ME, Guerin AP, et al. Aortic pulse wave velocity index and mortality in end-stage renal disease. Kidney Int 2003; 63: $1852-60$.

[9] London GM, Guerin AP, Marchais SJ, et al. Arterial media calcification in end-stage renal disease: impact on all-cause and cardiovascular mortality. Nephrol Dial Transplant 2003; 18: 1731-40.

[10] Verbeke F, Van Biesen W, Honkanen E, et al. CORD Study Investigators. Prognostic value of aortic stiffness and calcification for cardiovascular events and mortality in dialysis patients: outcome of the calcification outcome in renal disease (CORD) study. Clin J Am Soc Nephrol 2011; 6: 153-9.

[11] Gauthier-Bastien A, Ung RV, Larivière R, Mac-Way F, Lebel M, Agharazii M. Vascular remodelling and media calcification increases arterial stiffness in chronic kidney disease. Clin Exp Hypertens 2013; Jun 20. [Epub ahead of print].

[12] Cannata-Andia JB, Roman-Garcia P, Hruska K. The connections between vascular calcification and bone health. Nephrol Dial Transplant 2011; 26: 3429-36.

[13] Ross R. Atherosclerosis--an inflammatory disease. N Engl J Med 1999; 340: 115-26.

[14] London GM. Arteriosclerosis and arterial calcifications in chronic kidney insufficiency. Nephrol Ther 2005; 1 (Suppl 4): S351-4.

[15] London GM, Marchais SJ, Guerin AP, Metivier F, Adda H. Arterial structure and function in end-stage renal disease. Nephrol Dial Transplant 2002; 17: 1713-24.

[16] Pateinakis P, Papagianni A, Douma S, Efstratiadis G, Memmos D. Associations of fetuin-A and osteoprotegerin with arterial stiffness and early atherosclerosis in chronic hemodialysis patients. BMC Nephrol 2013; 14: 122.

[17] Rodríguez-García M, Gómez-Alonso C, Naves-Díaz M, DiazLopez JB, Diaz-Corte C, Cannata-Andía JB; Asturias Study Group. Vascular calcifications, vertebral fractures and mortality in haemodialysis patients. Nephrol Dial Transplant 2009; 24: 239-46.

[18] Naves M, Rodríguez-García M, Díaz-López JB, Gómez-Alonso C, Cannata-Andía JB. Progression of vascular calcifications is associated with greater bone loss and increased bone fractures. Osteoporos Int 2008; 19: 1161-6.

[19] Giallauria F, Ling SM, Schreiber C, et al. Arterial stiffness and bone demineralization: the Baltimore longitudinal study of aging. Am J Hypertens 2011; 24: 970-5.

[20] Al-Aly Z, Shao JS, Lai CF, et al. Aortic Msx2-Wnt calcification cascade is regulated by TNF-alpha-dependent signals in diabetic Ldlr-/- mice. Arterioscler Thromb Vasc Biol 2007; 27: 2589-96.

[21] Román-García P, Carrillo-López N, Fernández-Martín JL, NavesDíaz M, Ruiz-Torres MP, Cannata-Andía JB. High phosphorus diet induces vascular calcification, a related decrease in bone mass and changes in the aortic gene expression. Bone 2010; 46: 121-8.

[22] Claes KJ, Viaene L, Heye S, Meijers B, d'Haese P, Evenepoel P. Sclerostin: another vascular calcification inhibitor? J Clin Endocrinol Metab 2013; 98: 3221-8.

[23] Hampson G, Edwards S, Conroy S, Blake GM, Fogelman I, Frost ML. The relationship between inhibitors of the Wnt signalling pathway (Dickkopf-1(DKK1) and sclerostin), bone mineral density, vascular calcification and arterial stiffness in post-menopausal women. Bone 2013; 56: 42-7.

[24] Qunibi WY. Reducing the burden of cardiovascular calcification in patients with chronic kidney disease. J Am Soc Nephrol 2005; 16 (Suppl 2): S95-S102.

[25] Othmane Tel H, Bakonyi G, Egresits J, et al. Effect of sevelamer on aortic pulse wave velocity in patients on hemodialysis: a prospective observational study. Hemodial Int 2007; 11 (Suppl 3): S13-S21.

[26] Braun J, Asmus HG, Holzer H, et al. Long-term comparison of a calcium-free phosphate binder and calcium carbonate--phosphorus 
metabolism and cardiovascular calcification. Clin Nephrol 2004; 62: 104-15.

[27] Qunibi W, Moustafa M, Muenz LR, et al. CARE-2 Investigators. A 1 -year randomized trial of calcium acetate versus sevelamer on progression of coronary artery calcification in hemodialysis patients with comparable lipid control: the Calcium Acetate Renagel Evaluation-2 (CARE-2) study. Am J Kidney Dis 2008; 51: 952-65.

[28] Raggi P, Chertow GM, Torres PU, et al. ADVANCE Study Group. The ADVANCE study: a randomized study to evaluate the effects of cinacalcet plus low-dose vitamin D on vascular calcification in patients on hemodialysis. Nephrol Dial Transplant 2011; 26: 132739.

[29] Ureña-Torres PA, Floege J, Hawley CM, et al. Protocol adherence and the progression of cardiovascular calcification in the ADVANCE study. Nephrol Dial Transplant 2013; 28: 146-52.

[30] Mathew S, Lund RJ, Chaudhary LR, Geurs T, Hruska KA. Vitamin D receptor activators can protect against vascular calcification. $\mathrm{J}$ Am Soc Nephrol 2008; 19: 1509-19.

[31] Katsiki N, Koumaras C, Athyros VG, Karagiannis A. Thinking beyond traditional cardiovascular risk factors: The role of arterial stiffness in targeting residual risk. Angiology 2012; 63: 9-11.

[32] Guérin AP, Pannier B, Marchais SJ, London GM. Cardiovascular disease in the dialysis population: prognostic significance of arterial disorders. Curr Opin Nephrol Hypertens 2006; 15:105-10.

[33] Koumaras C, Tzimou M, Stavrinou E, et al. Role of antihypertensive drugs in arterial 'de-stiffening' and central pulsatile hemodynamics. Am J Cardiovasc Drugs 2012; 12: 143-56.
[34] Guerin AP, Blacher J, Pannier B, Marchais SJ, Safar ME, London GM. Impact of aortic stiffness attenuation on survival of patients in end-stage renal failure. Circulation 2001; 103: 987-92.

[35] Williams B, Lacy PS, Thom SM, et al. CAFE Investigators; AngloScandinavian Cardiac Outcomes Trial Investigators; CAFE Steering Committee and Writing Committee. Differential impact of blood pressure-lowering drugs on central aortic pressure and clinical outcomes: principal results of the Conduit Artery Function Evaluation (CAFE) study. Circulation 2006; 113: 1213-25.

[36] Edwards NC, Steeds RP, Stewart PM, Ferro CJ, Townend JN. Effect of spironolactone on left ventricular mass and aortic stiffness in early-stage chronic kidney disease: a randomized controlled trial. J Am Coll Cardiol 2009; 54: 505-12.

[37] Fassett RG, Robertson IK, Ball MJ, Geraghty DP, Sharman JE, Coombes JS. Effects of atorvastatin on arterial stiffness in chronic kidney disease: a randomised controlled trial. J Atheroscler Thromb 2010; 17: 235-41.

[38] Westenfeld R, Ketteler M, Brandenburg VM. Anti-RANKL therapy--implications for the bone-vascular-axis in CKD? Denosumab in post-menopausal women with low bone mineral density. Nephrol Dial Transplant 2006; 21: 2075-7.

[39] Padhi D, Jang G, Stouch B, Fang L, Posvar E. Single-dose, placebo-controlled, randomized study of AMG 785, a sclerotic monoclonal antibody. J Bone Miner Res 2011; 26: 19-26.

Received: October 13, 2013

Revised: October 15, 2013

Accepted: October 15, 2013

(C) Stavrinou et al.; Licensee Bentham Open.

This is an open access article licensed under the terms of the Creative Commons Attribution Non-Commercial License (http://creativecommons.org/licenses/by-nc/3.0/) which permits unrestricted, non-commercial use, distribution and reproduction in any medium, provided the work is properly cited. 